Simon Twose \& Andrew Barrie, "Familial Clouds" in Traces of Centuries \& Future Steps, Palazzo Bembo, Venice, Italy, 2012. [Photo: Simon Twose]
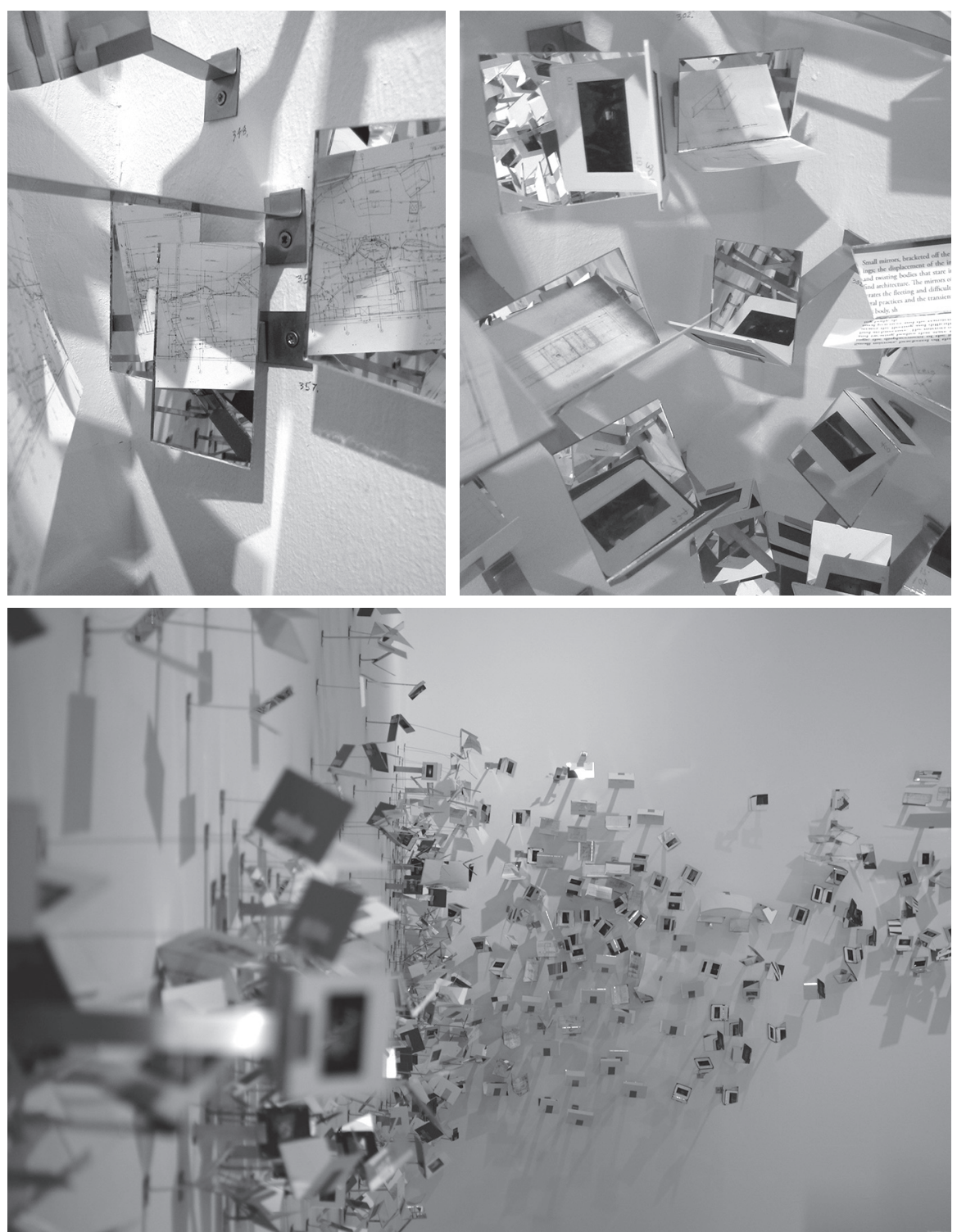


\title{
Familial Clouds
}

\author{
An exhibition by Simon Twose and Andrew Barrie \\ Review by Tom Daniell
}

New Zealand has no permanent presence at the Venice Architecture Biennale, no national pavilion in the Giardini, yet in 1991 its first (and, until now, only) contribution was an incredible success. As part of an exhibition of selected architecture schools from around the world, Auckland was awarded the "Venice Prize" at the urging of Arata Isozaki and other members of the jury - no doubt to the shock and chagrin of all the inestimably more famous architecture schools favoured to win. Disappointingly, this wasn't enough to convince those with the authority to make such decisions that it would be worth funding regular New Zealand participation in Venice (though, to be fair, in recent years New Zealand artists have been showing in the "real" Venice Biennale, an international art show that alternates with the Architecture Biennale). It did, at least briefly, put the Auckland School of Architecture front and centre within the world architectural community's consciousness.

The demonstrable brilliance of the work proffered by Auckland in 1991 aside, one has to hand it to Isozaki. As a frequent juror for major architecture competitions, his insistence on championing the most radical, unlikely designs has led to the recognition (though not always the realisation) of some of the most influential projects of recent decades - Bernard Tschumi's Parc de la Villette, Zaha Hadid's Peak, Itsuko Hasegawa's Shonandai Cultural Center, Foreign Office Architects' Yokohama International Port Terminal, Toyo Ito's Sendai Mediatheque, for example - not only jumpstarting the careers of relative unknowns and allowing established figures to produce definitive works, but accelerating the evolution of the discipline itself.

Twenty years after Auckland's 15 minutes of fame, a few of the protagonists were back together at the $13^{\text {th }}$ Venice Architecture Biennale in 2012. Isozaki was joined by Simon Twose and Andrew Barrie (members of Auckland's original student team, and now academics at Victoria University of Wellington and The University of Auckland respectively) in an exhibition called "Traces of Centuries \& Future Steps", which included about 60 architects from 26 countries. Organised by the Global Art Affairs Foundation, a Dutch non-profit organisation that "aims to heighten the awareness about the more philosophical themes in contemporary art", this was described as a "collateral event of the $13^{\text {th }}$ International Architecture Exhibition", one of several independent exhibitions that took place parallel to the Biennale proper. It was located in the magnificent Palazzo Bembo, a restored fifteenth-century aristocratic home facing the Grand Canal, a few steps from the Rialto Bridge and about 15 minutes by vaporetto from the Biennale venues.

The double title comes from the two centrepieces of the exhibition. On the lower floor was "Traces of Centuries" by Chinese artist Ying Tianqi, a multi-room, multimedia reflection on the modernization of China. On the upper floor was "Future Steps" by Arata Isozaki, showing his urban development proposal for Zhengzhou, China - an interactive installation that invites visitors to physically alter it, thus forming a trilogy with his 1962 "Incubation Process" and 1997 "Mirage City" exhibitions. The other 30 or so rooms contained projects from selected architects, each working in collaborative pairs or small groups. The exhibits ranged from conventional displays of architectural drawings and models to sound-and-light media installations, in some cases escaping their assigned galleries into the adjacent
Familial Clouds, by Simon Twose \& Andrew Barrie

Traces of Centuries \& Future Steps Collateral Event of the $13^{\text {th }}$ International Architectural Exhibition, La Biennale di Venezia

Palazzo Bembo, Venice, Italy, August 29 to November 25, 2012 
Simon Twose \& Andrew Barrie, "Familial Clouds" in Traces of Centuries \& Future Steps, Palazzo Bembo, Venice, Italy, 2012. [Photo: Patrick Loo]

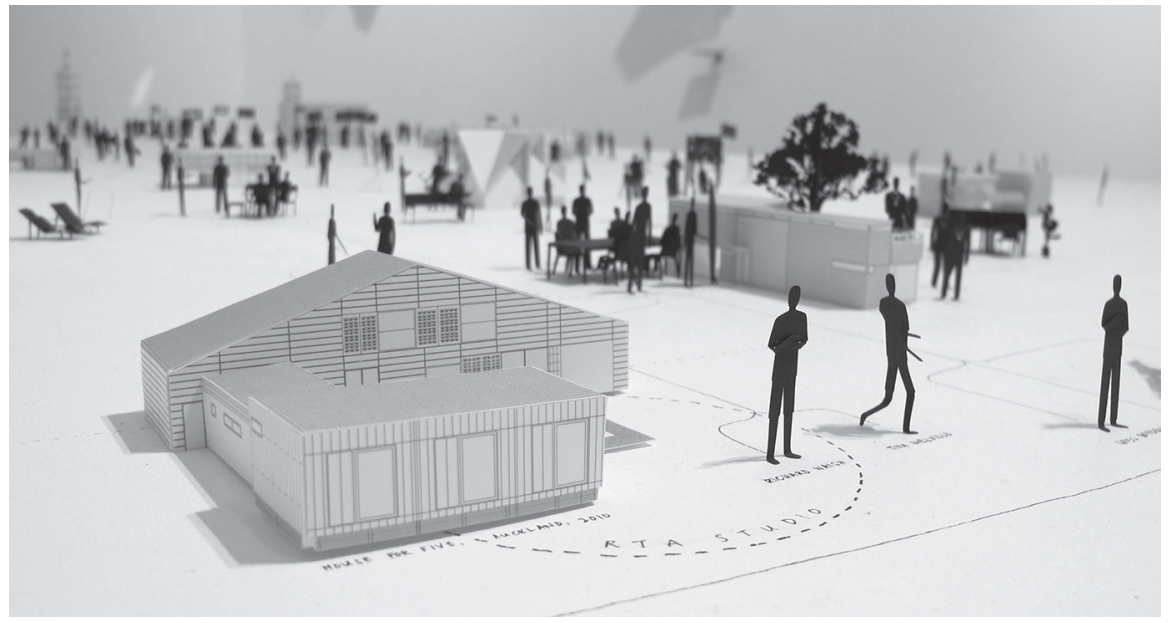

corridors or courtyards. All were invited as a result of an open call for proposals Twose and Barrie were there on their own merits, not as representatives of a nation.

Nonetheless, the installation explicitly presented itself as a component of the wider New Zealand architectural scene and its historical development. Titled "Familial Clouds", the room was dominated by a large white plinth acting as a backdrop for a diagrammatic diorama of the historical lineages that weave through New Zealand architecture from the colonial period onward. Lineages of people, that is, not styles. Like a genealogical chart of marriages and offspring, we were shown working partnerships and collaborations, generational sequences of students and teachers, and the shifting relationships between employees and employers, all presented as a complex (and, Barrie admits, controversial) web of mutual influence. Well-suited to the 2012 Biennale theme "Common Ground", this was the latest iteration of research begun by Barrie in 2008, initially as a flow chart of names, now manifested as an array of labelled human silhouettes complemented, for more-or-less obscure reasons, with stylised trees, animals, furniture, flags, musical instruments, and so on. All the figures are black, with two exceptions: Twose and Barrie are both shown in red, the focal points of the display and the culmination of the lineages. In a characteristically Kiwi mixture of modesty and egotism, the exhibit is an extraction of their own disciplinary family trees from the wider New Zealand architectural community.

Even as straight documentation lacking critique or analysis, this has a certain value for future historians. Now that the circuitry is so revealed with such clarity, we can better address the information being passed along it: the ways in which the stylistic and technical evolution of New Zealand architecture has been facilitated and advanced by its substrate of personal relationships. A first step has been made here by the inclusion of simple paper models of key buildings standing next to the figures of their architects. Models of two designs each by Twose and Barrie blended in with the other artefacts. Twose showed a pair of award-winning 
houses, one in Wellington and the other in Auckland. As well as models set on the plinth, they were dissected into hundreds of tiny pieces dispersed across the walls, showing the design processes and built results: a cloud of fragmentary models, $35 \mathrm{~mm}$ slides, shrunken hand sketches and computer drawings, all set at odd angles and interspersed with tiny mirrors necessary for seeing some of the images. Barrie presented finely crafted models of two intriguing unbuilt projects. Though given nominal programs and locations, they were essentially experiments in using rationalised structural elements to achieve formal interest or surface articulation with minimal effort and resources.

That's a strategy that underlies the whole project. Twose and Barrie prefabricated most of the installation in Wellington and Auckland, then, like George Jetson's flying car, folded it into a parcel that weighed less than a kilo and carried it in their hand luggage to Venice. In both its content and method, the installation is an ingenious demonstration of the kind of nimble, unpretentious approach that can enable a small, often overlooked Pacific nation to participate in a global discourse. From some angles, "Familial Clouds" might be seen as a slightly discomfiting attempt to establish credibility through provenance rather than material results. Nonetheless, in emphasising the wider ecology and history of architectural practice in New Zealand, Twose and Barrie suggest the ways in which any individual design is constrained and enabled by being unavoidably embedded within a specific place and time. Ultimately, it's less a show of work than a presentation of evidence that work is being done.

Arata Isozaki toured the Palazzo Bembo before the exhibition opened to the public, and met Twose and Barrie. When he learned where they were from, he mentioned that many years ago he had been on a Biennale jury and found "one excellent project" deserving of the Venice Prize, an installation in the shape of a cloud from a school in New Zealand. To then discover that he was encountering new clouds from two of those original students was a small yet invaluable vindication for everyone involved.

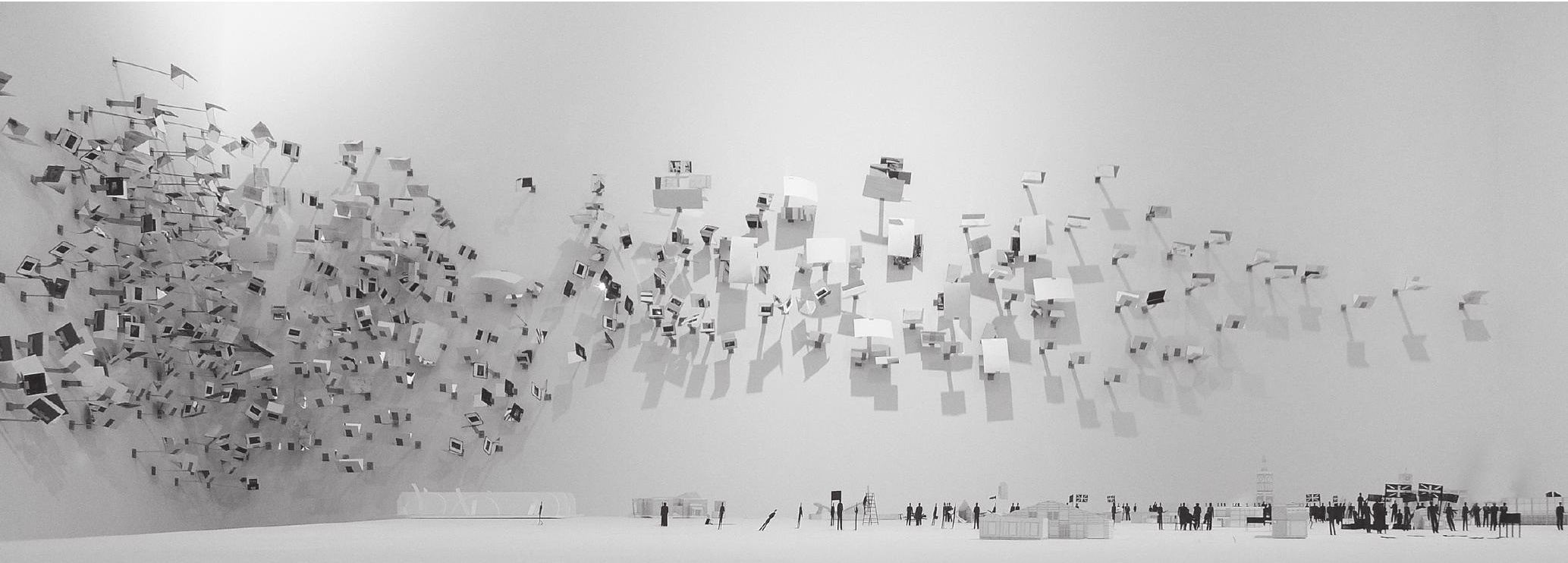

